\title{
Dampak Program Nasional Pemberdayaan Masyarakat (PNPM) Mandiri Perdesaan terhadap Pendapatan Petani Desa Paslaten, Kecamatan Tatapaan, Kabupaten Minahasa Selatan
}

\author{
Anggita Nonoy \\ Eyverson Ruauw \\ Ribka M. Kumaat
}

\begin{abstract}
This study aims to determine the impact of the PNPM Mandiri activities to the income of farmers. Research conducted in September through December 2016. The data used are primary data obtained through interviews to 20 (twenty) of the respondents in this case women's credit group (SPP) through the list of questions regarding before and after participating in PNPM-MP and secondary data obtained from the District Office and the Office of Paslaten Tatapaan Sub-district. Analysis of the data used is the analysis kuantitattif using different test average by using the formula paired samples t-test. The results showed PNPM-MP have a positive impact where the income of farmers increasing from Rp.70,663,000 with an average of Rp. 3,533.150 to Rp. 126,397,250 with an average Rp.6,319,862.50,- so that it increases $78.87 \%$. Therefore this program can help in agriculture where it has been increasing farmers' income after the program PNPM-MP so farmers can expand their farming land.
\end{abstract}

Keywords : National Community Empowerment Program (PNPM-MP), Farmer Income, Paslaten Village, Sub-district of Tatapaan, South Minahasa District

\section{ABSTRAK}

Penelitian ini bertujuan untuk mengetahui dampak yang di timbulkan dari adanya kegiatan PNPM Mandiri Perdesaan terhadap pendapatan petani. Penelitian dilaksanakan pada bulan September sampai Desember 2016. Data yang digunakan adalah data primer yang diperoleh melalui wawancara kepada 20 (dua puluh) orang responden melalui daftar pertanyaan. Responden merupakan anggota kelompok Simpan Pinjam Perempuan (SPP). Data yang dikumpulkan adalah data sebelum dan sesudah mengikuti PNPM-MP. Data sekunder diperoleh dari Kantor Kecamatan Tatapaan dan Kantor Desa Paslaten. Analisis data yang digunakan adalah analisis kuantitattif dengan menggunakan uji beda rata-rata dengan menggunakan rumus uji-t sampel berpasangan. Hasil penelitian menunjukan Program PNPM-MP memberikan dampak yang positif di mana pendapatan petani yang mengikuti program ini telah meningkat dari Rp.70,663,000,- dengan rata-rata Rp. 3,533.150,- menjadi Rp. 126,397,250,- dengan rata-rata Rp.6,319,862.50,- sehingga mengalami peningkatan sebesar 78,87\%. Program ini membantu di bidang pertanian terutama petani dengan meningkatkan pendapatan petani sehingga petani mampu memperluas lahan garapan tempat berusahatani.

Kata Kunci : Program Nasional Pemberdayaan Masyarakat (PNPM-MP), Pendapatan Petani, Desa Paslaten, Kecamatan Tatapaan, Kabupaten Minahasa Selatan

\section{PENDAHULUAN}

Tujuan negara Indonesia, sebagaimana diamanatkan dalam Pembukaan Undang-Undang Dasar 1945 antara lain adalah memajukan kesejahteraan umum dan mencerdaskan kehidupan bangsa. Kesejahteraan umum atau kesejahteraan rakyat dapat ditingkatkan jika kemiskinan dapat dikurangi, sehingga untuk meningkatkan kesejahteraan umum dapat dilakukan melalui upaya penanggulangan kemiskinan. Dampak dari krisis yang dialami bangsa Indonesia sejak tahun 1997 yang paling nyata yakni kehidupan masyarakat miskin yang semakin miskin. Kemiskinan pada dasarnya bukan hanya permasalahan ekonomi tetapi lebih bersifat multidimensional dengan akar permasalahan terletak pada sistem ekonomi dan politik bangsa (Aprianti, 2011).

Kemiskinan merupakan masalah multidimensi dan lintas sektor yang dipengaruhi 
oleh berbagai faktor yang saling berkaitan, antara lain : tingkat pendapatan, kesehatan, pendidikan, askses terhadap barang dan jasa, lokasi, geografis, gender, dan kondisi lingkungan. Kemiskinan menjadi salah satu problem sosial yang amat serius. Dari ukuran kehidupan moderen saat ini mereka tidak memiliki fasilitas pendidikan, pelayanan kesehatan, dan kemudahan-kemudahan lainnya yang tersedia pada jaman modern (Rachmawati, 2011).

Untuk meningkatkan efektivitas penanggulangan kemiskinan dan penciptaan lapangan kerja maka salah satu jalan adalah dengan memberdayakan masyarakat. Pemberdayaan masyarakat merupakan salah satu upaya untuk meningkatkan kesejahteraan masyarakat melalui beberapa kegiatan antara lain peningkatan prakarsa dan swadaya masyarakat, perbaikan lingkungan dan perumahan, pengembangan usaha ekonomi desa, pengembangan lembaga keuangan desa, serta kegiatan-kegiatan yang dapat meningkatkan kemampuan masyarakat dalam meningkatkan hasil produksinya (Rahayu dan Purwidianti, 2014).

Pada tahun 2007 pemerintah mencanangkan Program Nasional Pemberdayaan Masyarakat Mandiri (PNPM MANDIRI) yang terdiri dari PNPM Mandiri Perdesaan, PNPM Mandiri Perkotaan, serta PNPM Mandiri wilayah khusus dan desa tertinggal. Pendekatan PNPM Mandiri merupakan pengembangan dari Program Pengembangan Kecamatan (PPK). Beberapa keberhasilan Program Pengembangan Kecamatan (PPK) adalah berupa penyediaan lapangan kerja dan pendapatan bagi kelompok rakyat miskin, efisiensi dan efektivitas kegiatan, serta berhasil menumbuhkan kebersamaan dan partisipasi masyarakat (Syukri, 2012).

Salah satu jenis kegiatan PNPM-MP ini adalah penambahan permodalan simpan pinjam untuk kelompok perempuan atau yang sering disebut dengan SPP. Dalam salah satu tujuan khususnya, disebutkan bahwwa PNPM-MP bertujuan untuk meningkatkan partisipasi seluruh masyarakat, khususnya rakyat miskin dan atau kelompok perempuan, dalam pengambilan keputusan perencanaan, pelaksanaan, pemantauan dan pelestarian pembangunan. Kegiatan simpan pinjam perempuan (SPP) merupakan salah satu jenis kegiatan yang secara nyata menunjukan adanya keseriusan dari PNPM-
MP untuk memprioritaskan pemberdayaan perempuan (Rachmawati, 2011).

Simpan Pinjam Perempuan (SPP) merupakan kegiatan pemberian dana bantuan permodalan untuk kelompok perempuan yang mempunyai kegiatan simpan pinjam. Program ini diharapkan mampu memecahkan persoalan perekonomian ditingkat masyarakat, yang pengelolaannya diserahkan kepada perempuan sebagai bagian yang juga bertanggungjawab pada perekonomian keluarga di pedesaan.melalui kegiatan simpan pinjam perempuan (SPP) diharapkan bisa merubah kondisi perekonomian di dalam masyarakat, khususnya anggota kelompok itu sendiri. Dengan adanya pengelolaan yang baik terhadap program simpan pinjam perempuan (SPP) di dalam kelompok, diharapkan program ini mampu menjadi alat dalam mengatasi masalah permodalan, menurunkan kemiskinan dan pengangguran sehingga masyarakat bisa merasakan kemakmuran dengan adanya program ini

Desa Paslaten kecamatan Tatapaan kabupaten Minahasa Selatan merupakan desa yang sebagian besar penduduknya berprofesi sebagai petani, yang terdiri dari 375 Kepala keluarga. Laki-laki 573 jiwa, perempuan 635 jiwa, jumlah 1208 jiwa. Jumlah petani 390 jiwa. Jumlah keluarga miskin 220 keluarga. Desa Paslaten merupakan salah satu desa yang menerima Program Nasional Pemberdayaan Masyarakat Mandiri Perdesaan (PNPM-MP) sejak tahun 2010. Bentuk-bentuk pembangunan fisik yang diterima yaitu pembangunan irigasi, drainase, jalan alternatif di kebun-kebun dan bantuan sosial bagi para lansia, sedangkan pembangunan non fisik adalah kegiatan simpan pinjam perempuan (SPP).

Tabel 1. Jenis tanaman dan luas lahan di Desa Paslaten

\begin{tabular}{cc}
\hline Jenis Tanaman & Luas Lahan $(\mathrm{Ha})$ \\
\hline Jagung & $\mathbf{1 5 0}$ \\
Cabe & $\mathbf{2}$ \\
Tomat & $\mathbf{5}$ \\
Padi Sawah & $\mathbf{2 3 0}$ \\
Kelapa & $\mathbf{2 1 0}$ \\
Cengkeh & $\mathbf{8 3 , 3 5}$ \\
Pala & $\mathbf{1 6 , 3}$ \\
\hline Jumlah & $\mathbf{6 8 6 , 6 5}$ \\
\hline
\end{tabular}

Sumber : Kantor Desa Paslaten, 2016 
Masyarakat yang menerima dana simpan pinjam perempuan (SPP) ada 86 anggota dari 7 kelompok yang ada di desa Paslaten dan yang mengalokasikan dana di bidang pertanian terutama Padi dan jagung ada 70 anggota dan yang lain digunakan untuk membuka usaha warung dan peternakan (Sumber : Kantor Kecamatan Tatapaan, 2016). Program Nasional Pemberdayaan Masyarakat Mandiri Perdesaan (PNPM-MP) diharapkan dapat membawa perubahan yang positif terlebih khusus di bidang pertanian. Karena sebagian besar dana yang diterima digunakan dalam bidang pertanian. Oleh sebab itu, penulis merasa perlu melakukan penelitian untuk mengetahui Dampak PNPM-Mandiri Perdesaan Terhadap Pendapatan Petani di Desa Paslaten Kecamatan Tatapaan Kabupaten Minahasa Selatan.

\section{Rumusan Masalah}

Dari latar belakang yang telah di uraikan diatas bahwa sebagian besar masyarakat desa paslaten adalah petani dan yang menerima dana simpan pinjam perempuan (SPP) sebagian besar di alokasikan di bidang pertanian terutama Padi dan Jagung. Oleh sebab itu yang menjadi masalah dalam penelitian adalah bagaimana dampak yang ditimbulkan dari Program Nasional Pemberdayaan Masyarakat (PNPM) Mandiri Pedesaan terhadap Pendapatan Petani Desa Paslaten Kecamatan Tatapaan Kabupaten Minahasa Selatan

\section{Tujuan Penelitian}

Tujuan yang ingin dicapai dalam penelitian ini adalah untuk mengetahui dampak dari adanya kegiatan PNPM Mandiri Perdesaan terhadap pendapatan petani Desa Paslaten Kecamatan Tatapaan Kabupaten Minahasa Selatan.

\section{Manfaat Penelitian}

Manfaat yang ingin dicapai dalam penelitian ini adalah untuk menambah pengetahuan bagi penulis dan memberikan informasi kepada masyarakat tentang dampak PNPM- Mandiri Perdesaan terhadap pendapatan petani Desa Paslaten Kecamatan Tatapaan Kabupaten Minahasa Selatan.

\section{METODE PENELITIAN}

\section{Waktu dan Tempat Penelitian}

Penelitian ini di laksanakan selama 4 bulan yaitu mulai dari bulan September sampai Desember tahun 2016 mulai dari persiapan sampai penyusunan laporan penelitian. Tempat penelitian ini dilaksanakan di Desa Paslaten Kecamatan Tatapaan Kabupaten Minahasa Selatan.

\section{Metode Pengumpulan Data}

Penelitian ini menggunakan data primer dan data sekunder. Data primer diperoleh dari pengamatan dan wawancara langsung dengan responden berdasarkan daftar pertanyaan (kuisioner) dengan data yang diperlukan adalah data sebelum dan sesudah mengikuti PNPMMandiri Perdesaan, sedangkan data sekunder dikumpulkan dan diperoleh melalui instansi yang terkait dengan penelitian ini antara lain dari Kantor Kecamatan Tatapaan dan Kantor Desa Paslaten Kecamatan Tatapaan Kabupaten Minahasa Selatan

\section{Metode Pengambilan Sampel}

Metode pengambilan sampel dalam penelitian ini menggunakan metode (simple random sampling) dimana jumlah respondenyang dijadikan sampel sebanyak 20 responden dari jumlah populasi sebanyak 70 anggota, dalam hal ini kelompok simpan pinjam perempuan (SPP) Desa Paslaten Kecamatan Tatapaan Kabupaten Minahasa Selatan.

\section{Konsep Pengukuran Variabel}

Adapun variabel-variabel yang akan diukur dalam penelitian ini adalah

1. Karateristik Responden :

a. Umur Petani (Tahun)

b. Tingkat Pendidikan (SD,SMP,SMA,PT)

2. Jenis Tanaman

3. Modal yang digunakan $(\mathrm{Rp})$

4. Luas Lahan Yang diusahakan (Ha)

5. Jenis Lahan yang digunakan (Milik Sendiri, Pinjam/lainnya)

6. Produksi yaitu jumlah produksi usaha pertanian dalam satu siklus tanam $(\mathrm{Kg})$

7. Harga yaitu harga yang berlaku ditingkat petani $(\mathrm{Rp} / \mathrm{Kg})$

8. Penerimaan yaitu Perkalian antara produksi dengan harga jual (Rp) 
9. Biaya terdiri atas 2 yaitu :

a. Biaya Tetap, yaitu biaya yang terdiri dari atas pajak $(\mathrm{Rp} / \mathrm{Ha})$, Penyusutan alat $(\mathrm{Rp})$

b. Biaya Variabel, yaitu biaya yang terdiri dari biaya tenaga kerja (Rp/HOK), Biaya pupuk (Rp/Kg), pestisida (Rp/kaleng), Benih $(\mathrm{Rp} / \mathrm{Kg})$ dan transportasi $(\mathrm{Rp})$, dan lain-lain (Rp)

10. Pendapatan $(\mathrm{Rp})$

\section{Metode Analisis Data}

Dalam penelitian ini metode analisis data yang di gunakan adalah analisis kuantitatif yaitu model analisis data berdasarkan atas hasil statistik, dan menggunakan Uji beda rata-rata menggunakan rumus Uji-T (Sampel berpasangan) karena yang akan di hitung adalah pendapatan petani sebelum dan sesudah mengikuti PNPM-Mandiri Perdesaan, dengan menggunakan aplikasi SPSS statistics 21.0

Di mana Rumus untuk Uji-T sampel berpasangan menurut Riadi (2016) dapat dilihat pada rumus dibawah ini :

$$
\mathrm{t}=\frac{\sum d_{i}}{\sqrt{\frac{N \sum \mathrm{d}_{\mathrm{i}}^{2}-\left(\sum \mathrm{d}_{\mathrm{i}}\right)^{2}}{N-1}}}
$$

\section{Gambar 3.1 Rumus Uji-T berpasangan}

Keterangan :

$\mathrm{T}=$ nilai $\mathrm{t}$

$\mathrm{d}=$ selisih nilai sebelum dan sesudah

$\mathrm{N}=$ Jumlah sampel

\section{HASIL DAN PEMBAHASAN}

\section{Profil Desa Paslaten}

Desa Paslaten merupakan salah satu desa di kecamatan Tatapaan. Desa Paslaten berada pada ketinggian $39 \mathrm{mdpl}$ (meter diatas permukaan laut). Desa paslaten terdiri dari 5 jaga. Jumlah penduduk desa paslaten terdiri dari Laki-laki 573 jiwa, perempuan 635 jiwa, jumlah 1208 jiwa. Batas Desa Paslaten :
a. Sebelah Utara : SM Manembo-nembo
b. Sebelah Timur : Desa Sulu
c. Sebelah Selatan : Teluk Amurang
d. Sebelah Barat : Desa Paslaten Satu

\section{Mata Pencaharian Pokok}

Data Penduduk menurut jenis pekerjaan yang ada di Desa paslaten berdasarkan pada jenis kelamin laki laki dan perempuan dapat dilihat pada Tabel 2.

Tabel 2. Mata Pencaharian Pokok Masyarakat Desa Paslaten

\begin{tabular}{lcc}
\hline Jenis Pekerjaan & Laki-laki & Perempuan \\
\hline - Petani & 383 orang & 5 orang \\
- Buruh Tani & 49 orang & 8 orang \\
- PNS & 10 orang & 21 orang \\
- Pengusaha kecil, & 14 orang & 2 orang \\
menengah dan besar & & \\
- Karyawan perusahaan & 14 orang & 13 orang \\
swasta & & \\
- Karyawan perusahaan & 4 orang & 3 orang \\
pemerintah & & \\
- Wiraswasta & 23 orang & 9 orang \\
- Ibu rumah tangga & 0 orang & 314 orang \\
- Purnawirawan/ & 7 orang & 13 orang \\
pensiunan & & \\
\hline Jumlah & $\mathbf{5 0 4}$ orang & $\mathbf{3 8 8}$ orang \\
\hline Sumber: Kantor Desa Paslatan 2016
\end{tabular}

Sumber : Kantor Desa Paslaten, 2016

\section{Luas Wilayah Menurut Penggunaan}

Data luas wilayah menurut penggunaannya yang ada di Desa Paslaten yang digunakan oleh masyarakat dapat dilihat pada Tabel 3.

Tabel 3. Luas wilayah menurut penggunaan di Desa Paslaten

\begin{tabular}{lc}
\hline \multicolumn{1}{c}{$\begin{array}{c}\text { Wilayah Menurut } \\
\text { Penggunaan }\end{array}$} & $\begin{array}{c}\text { Luas Lahan } \\
\text { (Ha) }\end{array}$ \\
\hline Tanah Sawah & 323 \\
Tanah Kering & 605 \\
Tanah Basah & 65 \\
Tanah Perkebunan & 699,5 \\
Tanah Hutan & 140 \\
Sawah Irigasi Teknis & 323 \\
Fasilitas Umum & 47,5 \\
Tegal/ladang & 550 \\
Tanah Rawah & 50 \\
Pasang Surut & 15 \\
Tanah Pemukiman & 30 \\
Tanah Pekarangan & 25 \\
Hutan Konservasi & 30 \\
Hutan Sekunder & 30 \\
Hutan Buatan & 25 \\
Hutan Rakyat & 50 \\
\hline Jumlah & $\mathbf{3 , 0 0 8}$ \\
\hline Sumber : Kantor Desa Paslaten, 2016
\end{tabular}




\section{Agama/Aliran Kepercayaan}

Data penduduk menurut agama/aliran kepercayaan yang ada di Desa Paslaten berdasarkan pada jenis kelamin laki-laki dan perempuan dapat dijelaskan pada Tabel 4.

Tabel 4. Agama Masyarakat Desa Paslaten

\begin{tabular}{lcc}
\hline Agama & Laki-laki & Perempuan \\
\hline Islam & 1 orang & 2 orang \\
Kristen & 621 orang & 584 orang \\
Katholik & 4 orang & 3 orang \\
\hline Jumlah & 626 orang & 589 orang \\
\hline
\end{tabular}

Sumber : Kantor Desa Paslaten, 2016

\section{Sarana dan Prasarana}

Data sarana dan prasarana yang digunakan oleh masyarakat di Desa Paslaten dapat dilihat pada Tabel 5 .

Tabel 5. Sarana dan Prasarana Desa Paslaten

\begin{tabular}{lc}
\hline Sarana dan Prasarana & Unit \\
\hline SD & 2 \\
SMP & 1 \\
Gereja & 4 \\
Puskesmas & 1 \\
Balai Desa & 1 \\
\hline Jumlah & 9 \\
\hline
\end{tabular}

Sumber : Kantor Desa Paslaten, 2016

\section{Tenaga Kerja}

Data penduduk tenaga kerja yang ada di Desa Paslaten berdasarkan pada jenis kelamin laki-laki dan perempuan dapat dijelaskan pada Tabel 6.

\section{Potensi Desa Paslaten}

Ada beberapa potensi yang ada di Desa Paslaten yang dapat di manfaatkan oleh masyarakat untuk meningkatkan pendapatan, antara lain :

\section{Subsektor Pertanian}

Sektor pertanian yang ada di Desa Paslaten yang dapat di manfaatkan oleh masyarakat dapat dilihat pada Tabel 7 .

\section{Subsektor Perkebunan}

Sektor perkebunan yang ada di Desa Paslaten yang dapat di manfaatkan oleh masyarakat dapat dilihat pada Tabel 8 .

\section{Subsektor Peternakan}

Sektor peternakan yang ada di Desa Paslaten yang dapat di manfaatkan oleh masyarakat dapat dilihat pada Tabel 9.

Tabel 6. Tenaga Kerja Penduduk Desa Paslaten

\begin{tabular}{lcr}
\hline Tenaga Kerja & Laki-laki & Perempuan \\
\hline Penduduk usia 18-65 tahun & 314 orang & 328 orang \\
Penduduk usia 18-65 tahun yang bekerja & 327 orang & 316 orang \\
Penduduk usia 18-56 tahun tidak bekerja & 14 orang & 12 orang \\
Penduduk usia 0-6 tahun & 72 orang & 69 orang \\
Penduduk masih sekolah 7-18 tahun & 140 orang & 118 orang \\
Penduduk usia 56 tahun ke atas & 85 orang & 81 orang \\
\hline Jumlah & $\mathbf{9 7 9}$ orang & $\mathbf{9 2 4}$ orang
\end{tabular}

Sumber : Kantor Desa Paslaten, 2016

Tabel 7. Subsektor pertanian Desa Paslaten

\begin{tabular}{lccl}
\hline Tanaman & Luas Produksi & Hasil Produksi & Nilai Produksi (Rp) \\
\hline Jagung & $150 \mathrm{Ha}$ & $4 \mathrm{Ton} / \mathrm{Ha}$ & $1,800,000.000$ \\
Cabe & $2 \mathrm{Ha}$ & $40 \mathrm{Ton} / \mathrm{Ha}$ & $1,600,000.000$ \\
Tomat & $5 \mathrm{Ha}$ & $40 \mathrm{Ton} / \mathrm{Ha}$ & $1,000,000.000$ \\
Padi Sawah & $230 \mathrm{Ha}$ & $5 \mathrm{Ton} / \mathrm{Ha}$ & $6,900,000.000$ \\
\hline Jumlah & $\mathbf{3 8 7} \mathrm{Ha}$ & $\mathbf{8 9} \mathrm{Ton} / \mathrm{Ha}$ & $\mathbf{1 1 , 3 0 0 , 0 0 0 . 0 0 0}$ \\
\hline
\end{tabular}

Sumber : Kantor Desa Paslaten, 2016

Tabel 8. Subsektor perkebunan Desa Paslaten

\begin{tabular}{lllr}
\hline Tanaman & Luas Produksi & Hasil Produksi & Nilai Produksi $($ Rp) \\
\hline Kelapa & $210 \mathrm{Ha}$ & $7,5 \mathrm{Ton} / \mathrm{Ha}$ & $11,340,000.000$ \\
Cengkeh & $83,35 \mathrm{Ha}$ & $3,5 \mathrm{Ton} / \mathrm{Ha}$ & $35,007,000.000$ \\
Pala & $16,3 \mathrm{Ha}$ & $7,8 \mathrm{Ton} / \mathrm{Ha}$ & $6,102,720.000$ \\
\hline Jumlah & $\mathbf{3 0 9 , 6 5} \mathrm{Ha}$ & $\mathbf{1 8 , 8}$ Ton/Ha & $\mathbf{5 4 , 4 4 9 , 7 2 0 . 0 0 0}$
\end{tabular}

Sumber : Kantor Desa Paslaten, 2016 
Tabel 9. Subsektor peternakan Desa Paslaten

\begin{tabular}{lccc}
\hline Jenis Produksi & Hasil Produksi (Ton) & Nilai Produksi (Rp) & Jumlah Terna (Ekor) \\
\hline Telur & 685,960 & $1,027.500$ & 2,223 \\
Daging & 62,960 & $5,270.000$ & 923 \\
\hline Jumlah & $\mathbf{7 4 8 , 9 2 0}$ & $\mathbf{6 , 2 9 7 . 5 0 0}$ & $\mathbf{3 , 1 4 6}$ \\
\hline
\end{tabular}

(Sumber : Kantor Desa Paslaten, 2016)

\section{Prosedur Peminjaman Simpan Pinjam Perempuan (SPP)}

Adapun tahapan yang harus dilalui dalam mendapatkan pinjaman dana simpan pinjam perempuan (SPP) adalah sebagai berikut:

a. Pengajuan Usulan Pinjaman Kelompok

Kelompok membuat usulan proposal dan mengajukan usulan proposal tersebut kepada unit pelaksana kegiatan (UPK) yang ada di tingkat kecamtan sesuai dengan ketentuan yang telah ditetapkan oleh badan kerjasama antar desa (BKAD).

b. Evaluasi Singkat Usulan Pinjaman oleh Unit Pelaksana Kegiatan (UPK).

Unit pelaksana kegiatan (UPK) melakukan evaluasi singkat tentang latar belakang dari kelompok yang mengusulkan pinjaman dana, kondisi kelompok saat ini, riwayat pinjaman dana kelompok pada UPK, rencana usaha dan rencana penggunaan dana pinjaman. Evaluasi singkat ini disampaikan bersamaan dengan usulan kelompok kepada tim verifikasi.

c. Verifikasi oleh Tim Verifikasi

Tim verifikasi melakukan verifikasi usulan sesuai dengan ketentuan yang telah ditetapkan oleh BKAD

d. Keputusan Pendanaan

Keputusan pendanaan dilakukan oleh tim yang telah ditetapkan oleh BKAD sesuai dengan ketentuan pendaan yang telah

$$
\text { Sebelum anggota kelompok }
$$

mendapatkan pinjaman dana dari SPP, semua kelompok pemanfaat harus memenuhi persyaratan-persyaratan pinjaman antara lain :

a. Pendataan calon peminjam dana SPP dengan membawa fotocopy KTP suami istri.

b. Pengarahan kepada calon peminjam tentang aturan pinjaman dan cara pembayaran angsuran pinjaman dari pengelola

c. Pengarahan pada calon peminjam tentang pemanfaatan dana pinjaman agar digunakan sebaik-baiknya untuk meningkatkan usaha, agar dapat memperbaiki keadaan ekonomi keluarga.

d. Mengajak musyawarah kepada anggota untuk kelangsungan kegiatan simpan pinjam agar semua anggota yang belum mendapatkan pinjaman akan mendapatkan pinjaman pada waktu yang akan datang

e. Mengisi surat pernyataan jika ada anggota kelompok yang tidak membayar angsuran pokok dan bunga pinjaman maka secara kelompok akan bersama-sama melunasinya.

f. Anggota kelompok harus membayar tepat waktu.

\section{Profil Penerima Dana PNPM-MP}

Pada penelitian ini profil penerima PNPM-MP dapat dilihat dari usia, pendidikan terakhir, jumlah pinjaman terakhir, lama usaha, lama menerima dana PNPM-MP, jangka waktu angsuran.

\section{Usia Responden}

Distibusi responden berdasarkan usia dapat dilihat pada tabel sebagai berikut :

Tabel 10. Rekapitulasi Data Usia Responden

\begin{tabular}{lcc}
\hline Usia & Jumlah & Persentase (\%) \\
\hline$<30$ Tahun & 2 & 10 \\
30-39 Tahun & 6 & 30 \\
40-49 Tahun & 4 & 20 \\
50-60 Tahun & 8 & \\
\hline Jumlah & $\mathbf{2 0}$ & $\mathbf{1 0 0}$ \\
\hline
\end{tabular}

Sumber : Data primer diolah, 2016

Berdasarkan Tabel 10 tersebut diketahui bahwa penerima dana PNPM-MP memiliki umur $<30$ tahun berjumlah 2 orang dengan persentase 10\%, umur 30-39 tahun berjumlah 6 responden dengan persentase 30\%, umur 40-49 tahun berjumlah 4 responden dengan persentase $20 \%$, dan umur 50 tahun ke atas berjumlah 8 responden dengan persentase $40 \%$. Ini menunjukan bahwa kebanyakan masyarakat yang mengikuti PNPM-MP ada di sekitar umur 50- 60 tahun. 


\section{Pendidikan Responden}

Distribusi responden berdasarkan pendidikan dapat dilihat pada tabel sebagai berikut :

Tabel 11. Rekapitulasi Data Pendidikan Responden

\begin{tabular}{lcc}
\hline Pendidikan & Jumlah & Persentase (\%) \\
\hline SD & 6 & 30 \\
SMP & 3 & 15 \\
SMA & 8 & 40 \\
Perguruan Tinggi & 3 & 50 \\
\hline Jumlah & $\mathbf{2 0}$ & $\mathbf{1 0 0}$ \\
\hline
\end{tabular}

Sumber : Data primer diolah, 2016

Berdasarkan Tabel 11 tersebut diketahui bahwa penerima dana PNPM-MP dengan tingkat pendidikan SD berjumlah 6 orang dengan persentase $30 \%$, tingkat pendidikan SMP berjumlah 3 responden dengan persentase $15 \%$, tingkat pendidikan SMA berjumlah 8 responden dengan persentase $40 \%$, dan tingkat pendidikan di Perguruan Tinggi berjumlah 3 responden. Ini menunjukan bahwa tingkat pendidikan responden yang paling banyak ada di tingkat SMA dengan jumlah 8 responden.

\section{Jumlah Pinjaman Terakhir}

Distribusi responden berdasarkan jumlah pinjaman terakhir dapat dilihat pada tabel sebagai berikut :

Tabel 12. Rekapitulasi Data Berdasarkan Jumlah Pinjaman Terakhir Responden

\begin{tabular}{ccc}
\hline Jumlah Pinjaman (Rp) & Jumlah & $\begin{array}{c}\text { Persentase } \\
(\boldsymbol{\%})\end{array}$ \\
\hline $1,000.000-5,000.000$ & 15 & 75 \\
$6,000.000-10,000.000$ & 3 & 15 \\
$11,000.000-15,000.000$ & 2 & 10 \\
\hline Total & $\mathbf{2 0}$ & $\mathbf{1 0 0}$ \\
\hline
\end{tabular}

Sumber : Data primer diolah, 2016

Berdasarkan Tabel 12 tersebut diketahui bahwa penerima PNPM-MP dengan jumlah pinjaman terakhir sekitar Rp. 1,000.000 5,000.000.- berjumlah 15 responden dengan persentase $75 \%$, jumlah pinjaman terakhir Rp. $6,000.000-10,000.000$ berjumlah 3 responden dengan persentase $15 \%$, jumlah pinjaman terakhir Rp. 11,000.000 - 15,000.000 berjumlah 2 responden dengan persentase $10 \%$. Ini menunjukan bahwa yang jumlah pinjaman terakhir yang paling banyak ada di Rp.1,000.000 - 5,000.000 dengan jumlah 15 responden. Dari hasil wawancara dengan responden jumlah pinjaman setiap responden berbeda, hal itu di karenakan kemampuan dan kebutuhan dari setiap responden itu berbedabeda dan juga ketika melakukan pinjaman dana melalui proposal yang diajukan setiap kelompok itu berbeda-beda dalam mendapatkan pinjaman.

\section{Lama Usaha Responden}

Distribusi responden berdasarkan lama usaha responden dapat dilihat pada tabel sebagai berikut :

Tabel 13. Rekapitulasi Data Berdasarkan Lama Usaha Responden

\begin{tabular}{ccc}
\hline Lama Usaha & Jumlah & Persentase (\%) \\
\hline$<10$ Tahun & 6 & 30 \\
$10-20$ Tahun & 5 & 25 \\
$21-30$ Tahun & 4 & 20 \\
$31-40$ Tahun & 5 & 25 \\
\hline Total & $\mathbf{2 0}$ & $\mathbf{1 0 0}$ \\
\hline
\end{tabular}

Sumber : Data primer diolah, 2016

Berdasarkan Tabel 13 tersebut diketahui penerima PNPM-MP dengan lama usaha 1-10 tahun berjumlah 6 responden dengan persentase $30 \%$, lama usaha 10-20 tahun dengan jumlah 5 responden dengan persentase $25 \%$, lama usaha 20-30 tahun dengan jumlah 4 responden dengan persentase 20\%, lama usaha 30-40 tahun dengan jumlah 5 responden dengan persentase $25 \%$. Ini menunjukan bahwa lama usaha responden $<10$ tahun adalah yang paling banyak dengan jumlah 6 responden.

\section{Lama Menerima Dana PNPM-MP}

Distribusi responden berdasarkan lama menerima dana PNPM-MP dapat dilihat pada tabel sebagai berikut :

Tabel 14. Rekapitulasi Data Responde Berdasarkan Lama Menerima Dana PNPM-MP

\begin{tabular}{ccc}
\hline $\begin{array}{c}\text { Lama } \\
\text { Menerima Dana }\end{array}$ & Jumlah & $\begin{array}{c}\text { Persentase } \\
(\boldsymbol{\%})\end{array}$ \\
\hline $1-2$ kali & 2 & 10 \\
$3-4$ kali & 6 & 30 \\
$5-6$ kali & 3 & 15 \\
7 kali & 9 & 45 \\
\hline Total & $\mathbf{2 0}$ & $\mathbf{1 0 0}$ \\
\hline
\end{tabular}

Sumber : Data primer diolah, 2016 
Berdasarkan Tabel 14 tersebut diketahui penerima PNPM-MP dengan lama menerima dana PNPM-MP 1-2 kali berjumlah 2 responden dengan persentase 10\%,lama menerima dana PNPM-MP 3-4 kali berjumlah 6 responden dengan persentase 30\%, lama menerima dana PNPM-MP 5-6 kali berjumlah 3 responden dengan persentase $15 \%$, lama menerima dana PNPM-MP > 7 kali berjumlah 9 responden dengan persentase $45 \%$. Ini menunjukan bahwa lama menerima dana PNPM-MP yang paling banyak 7 kali dengan jumlah 9 responden. Dalam hasil wawancara dengan responden, penulis dapat menyimpulkan bahwa ada beberapa responden yang menerima dana pinjaman hanya 2,3, dan 4 kali hal itu dikarenakan responden merasah lelah karena setiap bulan mereka harus melakukan pengembalian bunga, sedangkan responden juga harus membiayai kebutuhan pokok mereka setiap hari. Menurut responden yang melakukan pinjaman 5,6,dan 7 kali hal itu dikarenakan responden merasa bahwa dengan melakukan pinjaman dana, sangat membantu dalam mereka melakukan usahatani mereka dan juga membuka usaha baru seperti berjualan makanan.

\section{Jangka Waktu Angsuran}

Distribusi responden berdasarkan jangka waktu angsuran dalam mengikuti kegiatan PNPM-MP dapat dilihat pada tabel sebagai berikut :

\section{Tabel 15. Rekapitulasi Data Responden Berdasarkan Jangka Waktu Angsuran}

\begin{tabular}{ccc}
\hline $\begin{array}{c}\text { Jangka Waktu } \\
\text { Angsuran }\end{array}$ & Jumlah & $\begin{array}{c}\text { Persentase } \\
(\mathbf{\%})\end{array}$ \\
\hline 10 Bulan & 20 & 100 \\
12 Bulan & 0 & 0 \\
\hline Total & $\mathbf{2 0}$ & $\mathbf{1 0 0}$ \\
\hline
\end{tabular}

Sumber : Data primer diolah, 2016

Berdasarkan Tabel 15 tersebut diketahui jangka waktu angsuran 10 bulan dengan jumlah 20 responden dengan persentase $100 \%$, jangka waktu angsuran 12 bulan dengan jumlah 0 responden dengan persentase $0 \%$. Ini jelas menunjukan bahwa mayoritas responden dengan jangka waktu angsuran 10 bulan yang paling banyak berjumlah 20 responden.

\section{Usaha Sebelum Mengikuti PNPM-MP}

\section{Luas Lahan Responden}

Distribusi usaha sebelum mengikuti PNPM-MP berdasarkan luas lahan responden dapat dilihat pada Tabel 16.

Berdasarkan Tabel 16 menunjukkan bahwa pada luas lahan $<0,5 \mathrm{Ha}$ pada jenis tanaman padi dengan jumlah 2 responden dan pada jenis tanaman jagung 5 responden sehingga didapat jumlah 7 responden dengan persentase $35 \%$, pada luas lahan 0,6 - 1 Ha pada jenis tanaman padi dengan jumlah 2 responden dan pada jenis tanaman jagung 8 responden sehingga didapat jumlah 10 responden dengan persentase $50 \%$, pada luas lahan $1,1-1,5 \mathrm{Ha}$ yang ada hanya responden dengan jenis tanaman jagung dengan jumlah 3 responden dengan persentase $15 \%$. Sehingga didapat ratarata 2 responden pada jenis tanaman padi dan rata-rata 5,3 pada jenis tanaman jagung. Ini menunjukan bahwa sebelum mengikuti PNPM luas lahan responden $0,6-1 \mathrm{Ha}$ yang paling banyak dengan jenis tanaman jagung.

Berdasakan pada lampiran 2 dengan jenis tanaman padi di dapat luas lahan 2,7 $\mathrm{Ha}$ dengan rata-rata $0.135 \mathrm{Ha}$. Pada jenis tanaman jagung didapat luas lahan 14,5 Ha dengan ratarata $0.725 \mathrm{Ha}$.

\section{Jenis Tanaman}

Distribusi usaha sebelum mengikuti PNPM-MP berdasarkan jenis tanaman responden dapat dilihat pada Tabel 17.

Berdasarkan Tabel 17 menunjukkan bahwa pada jenis tanaman padi dengan jumlah 4 responden dengan persentase $20 \%$, pada jenis tanaman jagung dengan jumlah 16 responden dengan persentase $80 \%$. Ini menunjukan bahwa sebelum mengikuti PNPM-MP responden paling banyak menanam tanaman jagung daripada tanaman padi. Dalam tabel 5.8 juga dapat dijelaskan mengapa hanya 4 responden yang menanam padi itu dikarenakan pada tahun 2009-2010 keadaan irigasi yang menjadi satusatunya pengairan untuk menanam tanaman padi tidak berfungsi dengan baik. Oleh sebab itu, kebanyakan petani mulai beralih menanam tanaman jagung yang tidak terlalu membutuhkan air yang banyak, dan pada saat itu juga tanaman jagung sudah mulai di cari oleh pembeli. 


\section{Status Lahan Yang Digunakan}

Distribusi usaha sebelum mengikuti PNPM-MP berdasarkan status lahan yang digunakan dapat dilihat pada Tabel 18

Berdasarkan Tabel 18 bahwa status lahan yang digunakan berdasarkan milik sendiri dengan jumlah 6 responden dengan persentase $30 \%$, pada status lahan yang digunakan melalui pinjaman dengan jumlah 14 responden dengan persentase $70 \%$. Ini menunjukan bahwa sebelum mengikuti PNPM-MP responden paling banyak menggunakan lahan milik orang lain dalam hal ini pinjam.

\section{Penerimaan}

Distribusi usaha sebelum mengikuti PNPM-MP berdasarkan penerimaan hasil produksi petani (jumlah produksi $\mathrm{x}$ harga jual) dapat dilihat pada Tabel 19.

Berdasarkan Tabel 19 bahwa pada jenis tanaman padi dengan jumlah 4 responden dengan jumlah luas lahan 2,7 Ha di dapat jumlah produksi 3,9 ton dengan harga jual Rp. 3,500 sehingga mendapat penerimaan Rp. 13,650.000. Pada jenis tanaman jagung dengan jumlah 16responden dengan luas lahan 14,5 Ha di dapat jumlah produksi 37,4 ton dengan harga jual Rp. 3,000 sehingga mendapat penerimaan Rp. 112.200,000. Sehingga total semua penerimaan berjumlah Rp. $125,850.000$ dengan rata-rata penerimaan setiap peserta sebesar Rp. 6,292.500

\section{Pengeluaran}

Distribusi usaha sebelum mengikuti PNPM-MP berdasarkan penjumlahan dari (pajak, penyusutan alat, tenaga kerja, pupuk, pestisida, benih, transportasi dan lain-lain) dapat dilihat pada Tabel 20.

Berdasarkan Tabel 20 bahwa sebelum mengikuti PNPM-MP pada jenis tanaman padi dengan 4 responden didapat jumlah pengeluaran Rp. 6,505.000 dengan rata-rata Rp. 1,626.250. Pada jenis tanaman jagung dengan 16 responden didapat jumlah pengeluaran $\mathrm{Rp}$. 48,682.000 dengan rata-rata 3,042.625. Sehingga total pengeluaran tanaman padi dan jagung dengan jumlah 20 responden di dapat Rp. 55,187.000 dengan rata-rata pengeluaran setiap peserta sebesar Rp. 2,759.350

\section{Pendapatan}

Distribusi usaha sebelum mengikuti PNPM-MP berdasarkan pendapatan hasil produksi petani (penerimaan - pengeluaran) dapat dilihat pada Tabel 21.

Berdasarkan Tabel 21 bahwa sebelum mengikuti PNPM-MP dengan 20 responden (Padi dan jagung) di dapat jumlah pendapatan petani Rp. 70,663,000. Ini didapat dari total penerimaan di kurang dengan total pengeluaran. Dengan rata-rata pendapatan setiap peserta berjumlah Rp. 3,533.150

Tabel 16. Rekapitulasi Data Responden Berdasarkan Luas Lahan Sebelum PNPM-MP

\begin{tabular}{|c|c|c|c|c|}
\hline \multirow[t]{2}{*}{ Luas Lahan (Ha) } & \multicolumn{2}{|c|}{ Jenis Tanaman } & \multirow[t]{2}{*}{ Jumlah } & \multirow[t]{2}{*}{ Persentase (\%) } \\
\hline & Padi & Jagung & & \\
\hline$<0,5$ & 2 & 5 & 7 & 35 \\
\hline $0,6-1$ & 2 & 8 & 10 & 50 \\
\hline $1,1-1,5$ & & 3 & 3 & 15 \\
\hline Total & 4 & 16 & 20 & 100 \\
\hline
\end{tabular}

Sumber : Data primer diolah, 2016

Tabel 17 Rekapitulasi Data Responden Berdasarkan Jenis Tanaman Sebelum PNPM-MP

\begin{tabular}{lcc}
\hline Jenis Tanaman & Jumlah & Persentase (\%) \\
\hline Padi & 4 & 20 \\
Jagung & 16 & 80 \\
\hline Total & $\mathbf{2 0}$ & $\mathbf{1 0 0}$ \\
\hline
\end{tabular}

Sumber : Data primer diolah, 2016

Tabel 18. Rekapitulasi Data Responden Berdasarkan Status Lahan Yang Digunakan Sebelum PNPM-MP

\begin{tabular}{lll}
\hline Status Lahan & Jumlah & Persentase (\%) \\
\hline Milik Sendiri & 6 & 30 \\
Pinjaman & 14 & 70 \\
\hline Total & $\mathbf{2 0}$ & $\mathbf{1 0 0}$ \\
\hline
\end{tabular}

Sumber : Data primer diolah, 2016 
Tabel 19. Rekapitulasi Data Responden Berdasarkan Penerimaan Usahatani Sebelum PNPM-MP

\begin{tabular}{lccccc}
\hline Tanaman & Responden & Luas Lahan (Ha) & $\begin{array}{c}\text { Jumlah } \\
\text { Produksi (Ton) }\end{array}$ & $\begin{array}{c}\text { Harga Jual } \\
\text { (RP) }\end{array}$ & $\begin{array}{c}\text { Penerimaan } \\
\text { (Rp) }\end{array}$ \\
\hline Padi & 4 & 2,7 & 3,9 & 3,500 & $13,650.000$ \\
Jagung & 16 & 14,5 & 37,4 & 3,000 & $112,200.000$ \\
\hline Total & $\mathbf{2 0}$ & $\mathbf{1 7 , 2}$ & $\mathbf{4 1 , 3}$ & & $\mathbf{1 2 5 , 8 5 0 . 0 0 0}$ \\
\hline
\end{tabular}

Sumber : Data primer diolah, 2016

Tabel 20. Rekapitulasi Data Responden Berdasarkan Pengeluaran Usahatani Sebelum PNPM-MP

\begin{tabular}{lll}
\hline Tanaman & Jenis Pengeluaran & Jumlah Pengeluaran (Rp) \\
\hline Padi & Pajak & 35,000 \\
& Penyusutan alat & 0 \\
& Tenaga kerja & $3,200.000$ \\
& Pupuk & $1,170.000$ \\
& Pestisida & $1,125.000$ \\
& Benih & 175,000 \\
& Transportasi & 300,000 \\
& Lain-lain & 500,000 \\
\hline Jagung & Pajak & 82,000 \\
& Penyusutan alat & 0 \\
& Tenaga kerja & $25,125.000$ \\
& Pupuk & $6,805.000$ \\
& Pestisida & $8,260.000$ \\
& Benih & $2,670.000$ \\
& Transportasi & $2,720.000$ \\
& Lain-lain & $3,035.000$ \\
\hline Total & & $\mathbf{5 5 , 1 8 7 . 0 0 0}$
\end{tabular}

Sumber : Data primer diolah, 2016

Tabel 21. Rekapitulasi Data Responden Berdasarkan Pendapatan Usahatani Sebelum PNPM-MP

\begin{tabular}{lllll}
\hline Tanaman & Responden & Penerimaan $($ Rp) & Pengeluaran $($ Rp) & Pendapatan $($ Rp) \\
\hline Padi & 4 & $13,650.000$ & $6,505.000$ & $7,145.000$ \\
Jagung & 16 & $112,200.000$ & $48,684.000$ & $63,518.000$ \\
\hline Total & $\mathbf{2 0}$ & $\mathbf{1 2 5 , 2 0 0 . 0 0 0}$ & $\mathbf{5 5 , 1 8 7 . 0 0 0}$ & $\mathbf{7 0 , 6 6 3 . 0 0 0}$ \\
\hline
\end{tabular}

Sumber : Data primer diolah, 2016

\section{Usaha Sesudah Mengikuti PNPM-MP}

\section{Luas Lahan Responden}

Distribusi usaha sesudah mengikuti PNPM-MP berdasarkan luas lahan responden dapat dilihat pada Tabel 22.

Berdasarkan Tabel 22 bahwa pada luas lahan 0,5 - $1 \mathrm{Ha}$ dengan jumlah 11 responden dengan persentase $55 \%$, pada luas lahan $1,1-1,5$ Ha dengan jumlah 3 responden dengan persentase $15 \%$, pada luas lahan 1,6 - 2 Ha dengan jumlah 3 responden dengan persentase $15 \%$, pada luas lahan 2,1 - 2,5 Ha dengan jumlah 1 responden dengan persentase 5\%, pada luas lahan 2,6 - $3 \mathrm{Ha}$ dengan jumlah 2 responden dengan persentase. Ini menunjukan bahwa sesudah mengikuti PNPM responden yang paling banyak ada pada luas lahan
0,5 - 1 Ha dengan 11 responden, hal juga menunjukan bahwa sesudah mengikuti PNPMMP responden dapat memperluas lahan hingga 3 $\mathrm{Ha}$, hal ini berbeda dengan sebelum responden mengikuti PNPM-MP..

Berdasarkan pada lampiran 2 dengan jenis tanaman jagung didapat luas lahan 28,7 $\mathrm{Ha}$ dengan rata-rata $1,435 \mathrm{Ha}$. Hal ini dikarenakan responden mendapat pinjaman modal sehingga dapat mempeluas lahan dalam berusahatani.

\section{Jenis Tanaman}

Distribusi usaha sesudah mengikuti PNPM-MP berdasarkan jenis tanaman responden dapat dilihat pada Tabel 23. 
Berdasarkan Tabel 23 bahwa sesudah mengikuti program PNPM-MP mayoritas responden menanam tanaman jagung dengan jumlah 20 responden dengan persentase $100 \%$. Ini dikarenakan mulai pada tahun 2010 masyarakat mulai menanam tanaman jagung karena tanaman jagung sudah banyak di cari oleh pembeli. Petani merasa menanam jagung lebih praktis, hemat waktu, biaya dan tenaga dari pada menanam tanaman padi. Oleh karena itu, petani mulai beralih menanam tanaman jagung bahkanpun lahan tanaman padi di jadikan sebagai lahan tanaman jagung hal itu dikarenakan irigasi yang rusak dan masih dalam tahap perbaikan sampai tahun 2016. Bahkan sekarang masyarakat di Desa Paslaten sekitar $80 \%$ sudah beralih menanam tanaman jagung.

\section{Status Lahan Yang Digunakan}

Distribusi usaha sesudah mengikuti PNPM-MP berdasarkan status lahan yang digunakan dapat dilihat pada Tabel 24.

Berdasarkan Tabel 24 bahwa status lahan yang digunakan berdasarkan milik sendiri dengan jumlah 6 responden dengan persentase $30 \%$, pada status lahan yang digunakan melalui pinjaman dengan jumlah 14 responden dengan persentase $70 \%$. Ini menunjukan bahwa sesudah mengikuti PNPM-MP responden tetap sama dengan sebelum mengikuti PNPM-MP dengan tetap menggunakan lahan milik orang lain dalam hal ini pinjam.

\section{Penerimaan}

Distribusi usaha sesudah mengikuti PNPM-MP berdasarkan penerimaan hasil produksi petani (jumlah produksi x harga jual) dapat dilihat pada Tabel 25.
Berdasarkan Tabel 25 tersebut diketahui bahwa pada jenis tanaman jagung dengan jumlah 20 responden dengan luas lahan $28,7 \mathrm{Ha}$ di dapat jumlah produksi 73,7 ton dengan harga jual Rp. 3,000 sehingga mendapat penerimaan Rp. 221.100.000 dengan rata-rata penerimaan setiap peserta RP. 11,055.000. Ini membuktikan bahwa sesudah mengikuti PNPM-MP penerimaan petani mengalami peningkatan hal ini di ikuti dengan bertambahnya luas lahan dan jumlah produksi.

\section{Pengeluaran}

Distribusi usaha sesudah mengikuti PNPM-MP berdasarkan penjumlahan dari ( pajak, penyusutan alat, tenaga kerja, pupuk, pestisida, benih, transportasi dan lain-lain) dapat dilihat pada Tabel 26.

Berdasarkan Tabel 26 bahwa sesudah mengikuti PNPM-MP pada jenis tanaman jagung dengan 20 responden didapat jumlah pengeluaran $\mathrm{Rp}$. 94,702,750 dengan rata-rata pengeluaran setiap peserta Rp. 4,735,137.5. Ini menunjukan bahwa sesudah mengikuti PNPM pengeluaran petani meningkat dari sebelum mengikuti PNPM-MP. Hal ini di pengaruhi oleh luas lahan yang lebih besar dari sebelum mengikuti PNPM-MP

Berdasarkan Tabel 27 bahwa sebelum mengikuti PNPM-MP dengan 20 responden di dapat jumlah pendapatan petani Rp. 126,397.250 dengan rata-rata pendapatan setiap peserta Rp. 6,319,862.5. Hal ini di dapat dari total penerimaan di kurang dengan total pengeluaran. Ini menunjukan bahwa sesudah mengikuti PNPM pendapatan petani meningkat dari sebelum mengikuti PNPM-MP.

Tabel 22. Rekapitulasi Data Responden Berdasarkan Luas Lahan Sesudah PNPM-MP

\begin{tabular}{|c|c|c|}
\hline \multirow[t]{2}{*}{ Luas Lahan (Ha) } & Jenis Tanaman & \multirow[t]{2}{*}{ Persentase $(\%)$} \\
\hline & Jagung & \\
\hline $0,5-1$ & 11 & 55 \\
\hline $1,1-1,5$ & 3 & 15 \\
\hline $1,6-2$ & 3 & 15 \\
\hline $2,1-2,5$ & 1 & 5 \\
\hline $2,6-3$ & 2 & 10 \\
\hline Total & 20 & 100 \\
\hline
\end{tabular}

Sumber : Data primer diolah, 2016 
Tabel 23. Rekapitulasi Data Responden Berdasarkan Jenis Tanaman Sesudah PNPM-MP

\begin{tabular}{lcc}
\hline Jenis Tanaman & Jumlah & Persentase (\%) \\
\hline Padi & - & - \\
Jagung & 20 & 100 \\
\hline Total & $\mathbf{2 0}$ & $\mathbf{1 0 0}$ \\
\hline
\end{tabular}

Sumber : Data primer diolah, 2016

Tabel 24. Rekapitulasi Data Responden Berdasarkan Status Lahan Yang Digunakan Sesudah PNPM-MP

\begin{tabular}{lcc}
\hline Status Lahan & Jumlah & Persentase (\%) \\
\hline Milik Sendiri & 6 & 30 \\
Pinjaman & 14 & 70 \\
\hline Total & $\mathbf{2 0}$ & $\mathbf{1 0 0}$ \\
\hline
\end{tabular}

Sumber : Data primer diolah, 2016

Tabel 25. Rekapitulasi Data Responden Berdasarkan Penerimaan Usahatani Sesudah PNPM-MP

\begin{tabular}{lccccc}
\hline Tanaman & Responden & Luas Lahan & $\begin{array}{c}\text { Jumlah } \\
\text { Produksi }\end{array}$ & Harga Jual & $\begin{array}{c}\text { Jumlah } \\
\text { Penerimaan }\end{array}$ \\
\hline Padi & - & - & - & - & - \\
Jagung & 20 & $28,7 \mathrm{Ha}$ & 73,7 Ton & Rp. 3000 & Rp. $221,100.000$ \\
\hline Total & 20 & $28,7 \mathrm{Ha}$ & $73,7 \mathrm{Ton}$ & & Rp. $221,100.000$ \\
\hline
\end{tabular}

Sumber : Data primer diolah, 2016

Tabel 26. Rekapitulasi Data Responden Berdasarkan Pengeluaran Usahatani Sesudah PNPM-MP

\begin{tabular}{|c|c|c|}
\hline Jenis Tanaman & Jenis Pengeluaran & Jumlah Pengeluaran (Rp) \\
\hline Padi & - & - \\
\hline \multirow[t]{9}{*}{ Jagung } & Pajak & 228,000 \\
\hline & Penyusutan alat & 741,250 \\
\hline & Tenaga kerja & $44,860.000$ \\
\hline & Pupuk & $12,492.500$ \\
\hline & Pestisida & $15,335.000$ \\
\hline & Benih & $4,211.000$ \\
\hline & Transportasi & $4,750.000$ \\
\hline & Lain-lain & $4,765.000$ \\
\hline & Bunga $(6 \%)$ & $7,320.000$ \\
\hline
\end{tabular}

Total

94,702.750

Sumber : Data primer diolah, 2016

Tabel 27. Rekapitulasi Data Responden Berdasarkan Pendapatan Usahatani Sesudah PNPM-MP

\begin{tabular}{ccccc}
\hline Tanaman & Responden & Penerimaan $($ Rp) & Pengeluaran $($ Rp) & Pendapatan $($ Rp) \\
\hline Padi & - & - & - & - \\
Jagung & 20 & $221,100.000$ & $94,702.750$ & $126,397.250$ \\
\hline Total & $\mathbf{2 0}$ & $\mathbf{2 2 1 . 1 0 0 . 0 0 0}$ & $\mathbf{9 4 , 7 0 2 . 7 5 0}$ & $\mathbf{1 2 6 , 3 9 7 . 2 5 0}$
\end{tabular}

Sumber : Data primer diolah, 2016

Analisis Uji beda rata-rata

Pengujian beda rata-rata Pendapatan Sebelum dan Sesudah mengikuti PNPM-MP dengan menggunakan aplikasi SPSS.

Berdasarkan pada lampiran 6 dimana DF (degree of freedom) $\mathrm{n}-1$ atau 20-1=19 sehingga memperoleh nilai signifikansi $0,039<0,05$ dengan demikian maka Ho di tolak dan $\mathrm{Ha}$ diterima. Sehingga terdapat perbedaan pendapatan petani sebelum dan sesudah mengikuti PNPM-MP. 


\section{KESIMPULAN DAN SARAN}

\section{Kesimpulan \\ Program PNPM-MP memberikan} dampak yang positif di mana pendapatan petani dari Rp.70,663,000 dengan rata-rata Rp. 3,533.150 menjadi Rp. 126,397,250 dengan rata-rata $\mathrm{Rp} .6,319,862.5$ sehingga mengalami peningkatan sebesar $78,87 \%$. Oleh sebab itu program ini dapat membantu di bidang pertanian hal ini ditunjukan dengan meningkatnya pendapatan petani setelah mengikuti program PNPM-MP. Petani dapat memperluas lahan tempat berusahatani dan juga program ini sangat membantu petani walaupun harus membayar bunga sebesar $2 \%$ setiap bulannya.

\section{Saran}

Program PNPM Mandiri Perdesaan ini sangat bermanfaat kepada masyarakat apa terlebih kepada para petani yang membutuhkan modal untuk mengembangkan usaha pertanian mereka. Oleh sebab itu program PNPM-MP dapat di pertahankan.

\section{DAFTAR PUSTAKA}

Badan Pusat Statistik Indonesia, 2015 Departemen Dalam Negeri, 2008

Aprianti, 2011. Analisis Program Pemberdayaan Masyarakat Dalam Penanggulangan Kemiskinan Kota Semarang. Skripsi. Universitas Diponegoro. Semarang. Diakses 10 September 2016)

Hernanto, 1993. Ilmu usahatani. Penebar Swadaya. Jakarta

Kaunang, Regylia., 2015. Dampak PNPM Mandir Perdesaan Terhadap Kesejahteraan Masyarakat Desa Wasian Kecamatan Dimembe Kabupaten Minahasa Utara. Skripsi. Universitas Sam Ratulangi. Manado.

Kawau, Delke., 2015. Kajian Pendapatan Usahatani Kelapa Dengan Diversivikasi Horizontal Pada Gapoktan Petani jaya Di Desa Poigar Kecamatan Sinonsayang Kabupaten Minahasa Selatan. Skripsi. Universitas Sam Ratulangi. Manado.
Mokoagow, Nita., 2009. Kajian Pinjaman Dana Bergulir Program Nasional Pemberdayaan Masyarakat (PNPM) Mandir Perkotaan di Kelurahan Molas Kecamatan Bunaken. Skripsi. Universitas Sam Ratulangi. Manado.

Mubyarto, 2004. Pengantar Ekonomi Pertanian. LP3ES Jakarta.

Muliani, 2011. Partisipasi Masyarakat Miskin Terhadap Penanggulangan Kemiskinan Dalam Program Nasional Pemberdayaan Masyarakat Mandiri (PNPM-M) Perkotaan di Desa Cadangampar Kecamatan Sukaraja Kabupaten Bogor Provinsi Jawa Barat. Skripsi. IPB Bogor. ( Diakses 10 September 2016)

Rachmawati, 2011. Analisis Dampak Program Nasional Pemberdayaan Masyarakat Mandiri Perdesaan (PNPM-MP) Terhadap Perekonomian Anggota Simpan Pinjam Usaha Ekonomi Produktif (UEP) Di Kecamatan Tangen Kabupaten Sragen. Tesis. Universitas Sebelas Maret. ( Diakses 25 Agustus 2016)

Rahayu, Purwidianti., 2014. Pengaruh Program Pemberdayaan Masyarakat Pedesaan Terhadap Tingkat Pendapatan Masyarakat di Kecamatan Kedungbanteng Kabupaten Banyumas. Skripsi. Universitas Muhammadiyah Purwokerto. Purwokerto. ( Diakses 17 September 2016). ISBN 978602-14930-2-1

Rahayu, Sri Lestari., 2012. Bantuan Sosial di Indonesia Sekarang dan Kedepan BOSJEMKESMAS-PNPM-Mandiri-PKH. Fokus Media. Bandung.

Riadi, 2016. Statistika Penelitian (Analisis Manual dan IBM SPSS). Cv. Andi Offset. Yogyakarta.

Sagala, 2009. Evaluasi Program Nasional Pemberdayaan Masyarakat Mandiri Perdesaan (Pnpm-Mp) Terhadap Pengembangan Sosio-Ekonomi Dan Kesejahteraan Masyarakat Di Kecamatan Balige Kabupaten Toba Samosir. Tesis. Universitas Sumatera utara. Medan. Diakses 20 September 2016) 
Setiaji, 2014. Dampak Program Pengembangan Usaha Agribisnis Pedesaan Terhadap Pendapatan Anggota Gabungan Kelompok Tani. Skripsi. Universitas Diponegoro. Semarang. ( Diakses 25 Agustus 2016)

Soekartawi, 1995. Pengantar Ekonomi Pertanian. LP3ES. Jakarta

2002. Analisis Usahatani. Universitas Indonesia. Jakarta.

Sugiono, 2011. Metode Penelitian Kuantitatif Kualitatif dan R\&D. Cv. Alfabeta. Bandung.

, 2015. Metode Peneltian Manajemen.Cv. Alfabeta. Bandung.
Suharjo, A dan Patong D., 2007. Usahatani. Institut Pertanian Bogor (IPB)

Sukimo, 2006. Pengantar Teori Mikro Ekonomi. PT. Raja Grafindo. Jakarta.

Syukri, 2012. Laporan Penelitian Studi Kualitatif Dampak PNPM Perdesaan. PNPM Support Facility. Jakarta.

Theresia, dkk., 2014. Pembangunan Berbasis Masyarakat Acuan Bagi Praktisi, Akademis dan Pemerhati Pengembangan Masyarakat. Alfabeta. Bandung. 